\title{
Coulisses
}

Revue de théâtre

13 | Hiver 1996

Varia

\section{Les nouveaux murs du CDN}

\section{Yves Deschamps}

\section{OpenEdition}

Journals

Édition électronique

URL : http://journals.openedition.org/coulisses/4297

DOI : $10.4000 /$ coulisses.4297

ISSN : 2546-9460

\section{Éditeur}

Presses universitaires de Franche-Comté

\section{Édition imprimée}

Date de publication : 1 janvier 1996

Pagination : 68-69

ISSN : 1150-594X

\section{Référence électronique}

Yves Deschamps, «Les nouveaux murs du CDN », Coulisses [En ligne], 13 | Hiver 1996, mis en ligne le 15 mars 2019, consulté le 05 octobre 2020. URL : http://journals.openedition.org/coulisses/4297 ; DOI : https://doi.org/10.4000/coulisses.4297

Ce document a été généré automatiquement le 5 octobre 2020.

Coulisses 


\title{
Les nouveaux murs du CDN
}

\author{
Yves Deschamps
}

Le jeudi $1^{\text {er }}$ Novembre 1995 ont été inaugurés en grande pompe les aménagements complémentaires du Centre Dramatique National, qui en font en quelque sorte un nouveau théâtre. La salle était comble, sans doute 337 personnes, sa nouvelle capacité d'accueil. Les discours d'inauguration ont été suivis de la première de Peepshow dans les Alpes de Markus Köbeli, mis en scène par René Loyon, et d'un coquetèle.

René Loyon a accueilli ses hôtes en dressant un bilan de son activité depuis sa nomination il y a cinq ans et a ouvert des perspectives. Le maire de Besançon, Robert Schwint, le président de région, $\mathrm{M}$. Chantelat se sont félicités de cette action concertée en faveur de la culture, participant à la notoriété de la Franche-Comté Au-delà des considérations locales, Yves Deschamps, inspecteur général de la création et des enseignements artistiques Théatre, a rappelé sa vocation d'un théâtre de création. Il a bien voulu donner à Coulisses son allocution.

\section{Pour un théâtre de création}

Yves Deschamps, Inspecteur général de la création et des enseignements artistiques Théâtre. 
1 C'est à la dernière minute mercredi que Jacques Bâillon a su qu'il ne pourrait pas être parmi vous ce soir. Il vous prie d'excuser cet empêchement qui est, malheureusement, réel.

C'est donc à moi qu'échoit cet honneur. Je m'en réjouis, d'une part, et le redoute un peu d'autre part.

Je m'en réjouis, parce qu'il est toujours émouvant d'ouvrir un nouveau théâtre. Certes, le CDN de Besançon a déjà une histoire mais il n'avait pas jusqu'ici d'outil de travail à la mesure de son rôle. C'est chose faite et c'est très bien. Je le redoute parce que je sais que le théatre est souvent mal compris, mal perçu. En Franche-Comté comme ailleurs.

\section{Le théâtre de création}

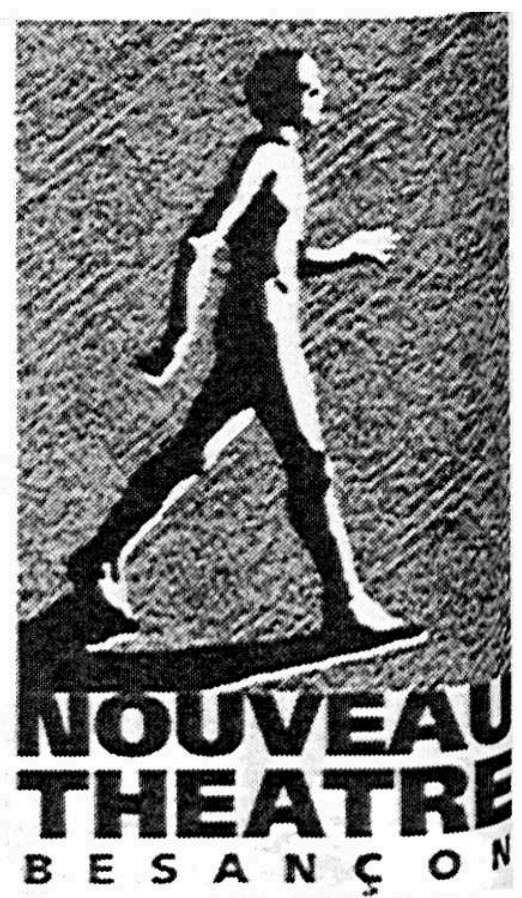

2 Le théâtre de création a souvent du mal (en opposition au théâtre de digestion).

Mais il faudrait être plus nuancé car les conformismes peuvent exister dans l'une et l'autre catégorie. Il reste que l'exclusion théatrale traverse toutes les couches sociales.

Bref le théâtre de création appartient à la famille de l'art, pas forcément à celle du délassement. Or, au-delà de son expression propre, la fonction sociale de l'art n'est-elle pas la mise en question de la culture ? Et chacun sait que cela ne va jamais de soi, et que de ce point de vue le théâtre est au croisement de tous les dangers.

D'abord, parce qu'il est éphémère. De plus il n'est pas, comme les arts plastiques, la musique, la littérature ou, plus encore, le cinéma, adossé à un marché ou à une industrie.

Ensuite et surtout, parce qu'il se trouve dans l'obligation de rencontrer son public dans l'instant. Vous savez en effet que sans cette rencontre/fusion entre la salle et le plateau, il n'y a pas de théâtre.

Sa fragilité fait sa grandeur. Car contrairement à un avis trop répandu, au théâtre, il n'y a pas de public passif ou captif. Chacun, à sa mesure, est tenu à participer. L'image transcendée que le théâtre offre au spectateur est celle de la société dans laquelle il se crée. Ces propositions demeurent, aujourd'hui encore, un incomparable instrument d'éveil, de réflexion, de dépassement et de plaisir.

\section{L'apprentissage du texte}

Il reste que cette fréquentation et ce plaisir se trouvent subordonnés à une initiation. Cela vaut pour toutes les activités humaines. L'apprentissage est la clé qui ouvre à la maîtrise, donc au plaisir.

Chacun sait cependant qu'il ne suffit pas d'apprendre à lire pour devenir un lecteur assidu. Il faut que cet apprentissage de la lecture (n'est-ce pas Pennac?) soit 
accompagné par l'apprentissage parallèle de la notion de plaisir. Il n'y a aucune raison pour que le théâtre soit épargné par cette règle. Or, il se trouve que spontanément chacun se voudrait immédiatement compétent en théâtre. Cela tient sans doute à son immense histoire.

Vous vous souvenez, sans doute, qu'à une période de cette histoire le théâtre, déjà considéré comme un outil pédagogique par excellence, était offert gratuitement aux spectateurs, on considérait qu'il était le véhicule rêvé qui permettrait la transmission des bases de la démocratie et de l'art de vivre.

Mieux encore, il est arrivé que l'on rétribue le spectateur afin qu'il bénéficie, de façon équitable, de la réflexion que les pièces d'Euripide ou de Sophocle proposaient pour le développement de la vie communautaire. Heureux Grecs !

5 Aujourd'hui, souvent copié et dénaturé par des spectacles de facilité, le Théâtre est assez mal compris et l'on a tendance a crié haro sur l'artiste, l'accablant, le rendant fautif de notre difficulté à pénétrer dans cet univers magique et grave.

6 Grave. Pas triste pour autant. Les artistes ne sont pas responsables de nos incapacités. En revanche, ne doivent-ils pas nourrir leur travail de création de cette indispensable proximité avec leurs publics sans pour cela altérer leur démarche artistique ? Il y a là, un véritable débat.

7 Son intérêt intrinsèque, le rempart qu'il n'a pas cessé d'être face à la prolifération de la bêtise, l'acte de résistance qu'il constitue contre l'uniformité des cultures et la vulgarité font du théâtre un art singulier qui justifie, toujours davantage, la sollicitude des collectivités publiques qui doivent, au-delà de leur différence, unir leurs efforts pour son développement.

\section{Le C.D.N., un pôle d'excellence et de référence}

8 Le Théâtre a besoin de lieux spécifiques pour se faire et se donner à voir et il n'est pas rentable. Ces données le fragilisent davantage encore et justifient pour partie l'aide publique, mais les parcs et jardins ne sont pas davantage rentables. Comme le théâtre ils participent à la qualité de la vie.

9 Aussi est-ce particulièrement émouvant d'être ici, aujourd'hui. Un théâtre de plus, bien équipé, c'est une pierre supplémentaire apportée à ce qui fait la grandeur de l'expression humaine : l'art.

10 Ma présence ici se voudrait témoignage. Elle permet par ailleurs de rappeler l'attachement de la D.T.S., donc du Ministère, à l'endroit de la Franche-Comté, de Besançon, et du Centre dramatique national de Besançon.

11 Nous voulons qu'il y ait ici, un C.D.N. parce que nous voulons que cette région bénéficie d'une meilleure structuration artistique et d'un pôle de référence qui complète les différents outils d'expression de diffusion existants. Nous ne perdons pas de vue, en particulier, le sud de la région et le département du Jura où se met en place une action intéressante qui mérite attention et soutien. Le nord est déjà mieux pourvu.

12 Pour revenir au département du Doubs et à la capitale régionale, nous pensons aussi qu'il y a lieu de procéder à une réflexion concertée afin qu'il y ait un juste équilibre entre le CDN, doté d'un nouvel équipement, et d'un nouveau dynamisme, le Théâtre municipal qui réajuste ses orientations afin que leurs actions soient harmonieusement articulées à celles de la scène nationale de Planoise. 
13 La mise en perspective de ce développement nécessitait que ces travaux, ici, soient réalisés. Et je voudrais saluer et féliciter René Loyon qui a su accomplir cette mission, car nous savons tous que la tâche n'était pas facile. Vous avez fait évoluer les choses dans le bons sens, mon cher Loyon, et au nom du Ministère, je vous en félicite et vous en remercie. Vous avez su faire gravir au CDN de Franche-Comté un échelon supplémentaire, et non des moindres, vers ce que doit être un CDN : un pôle d'excellence et de référence de la création dramatique, disposant de lieux de travail adaptés à cette fonction.

14 A partir de cette base acquise, il appartiendra au Ministère et à ses partenaires de redéfinir les perspectives d'évolution de cette institution nationale, inscrite au cœur du développement artistique et théâtral de la Franche-Comté.

\section{AUTEUR}

\section{YVES DESCHAMPS}

Inspecteur général de la création et des enseignements artistiques Théâtre. 